\title{
Avaliação das Percepções e Expectativas de Bacharelandos em Biologia: perfil e regulamentação profissional* $^{*}$
}

\author{
ISABELLA BANDEIRA OLIVEIRA, LOURIANE OLIVEIRA SILVA, \\ JULIANA MARIA HENRIQUES ESTEVÃO SOUZA \\ JULIANA PESSOA GOMES, LUCIANO RODOLFO FERREIRA LUCENA, \\ WELLINGTON SILVA AMARAL
}

Bacharelandos em Ciências Biológicas da Universidade Federal de Pernambuco

\begin{abstract}
SIMÃO DIAS VASCONCELOS
Professor Adjunto do Departamento de Zoologia da Universidade Federal de Pernambuco. Coordenador de Extensão do Centro de Ciências Biológicas da UFPE simaovasconcelos@yahoo.com.br
\end{abstract}

\begin{abstract}
Resumo
A avaliação da qualidade do ensino superior exige muito mais do que um teste dos conhecimentos "técnicos" socializados durante a graduação. É fundamental que o graduado saiba exatamente onde atuar, como seu perfil profissional se encontra regulamentado e o que lhe é permitido ou não desempenhar. Neste contexto, realizamos uma pesquisa com bacharelandos em Ciências Biológicas de três instituições de ensino superior de Recife, para avaliar suas percepções em relação ao mercado de trabalho, área de atuação e regulamentação da profissão. Observamos que a grande maioria desconhece seu perfil de atuação, e confunde as competências dos biólogos com as de outros profissionais. Há um bom conhecimento sobre o órgão regulamentador, mas a imensa maioria desconhece o piso salarial mínimo da categoria. Questionados sobre a motivação para a escolha do curso, a resposta mais freqüente foi "desenvolver pesquisa", e a carreira de pesquisador é a principal meta dos graduandos entrevistados. Sugere-se a inserção de temas relacionados à regulamentação da profissão do biólogo, com ênfase em legislação e ética, em disciplinas específicas ou atividades complementares ao longo do curso, para aperfeiçoar a formação acadêmica percebida.

Palavras-chave: avaliação, graduando, mercado, atuação, regulamentação, biólogos.

* Este artigo resulta de experiência didática da disciplina “Métodos da Investigação Científica", coordenada pelo professor Simão D. Vasconcelos. Agradecemos aos alunos da UFPE, UPE e Fafire pela ajuda na distribuição e aplicação dos questionários, especialmente ao facilitar o acesso à UPE e Fafire. Um agradecimento especial a todo os alunos que se dispuseram a responder aos questionários. Agradecemos também às biólogas Maria do Socorro Silva pela leitura crítica do manuscrito e Alice Carvalho Alencar Araripe, do Conselho Regional de Biologia, pelas informações gentilmente fornecidas à equipe.
\end{abstract}




\title{
Resumen
}

La evaluación de la cualidad de la enseñanza superior exige mucho mas que un simple teste de conocimientos "técnicos" socializados durante los estudios terciarios. Es fundamental que el graduado sepa exactamente donde actuar, cómo su perfil profesional se encuentra reglamentado y qué le es permitido o no desempeñar. En este contexto, realizamos una investigación con estudiantes de Ciencias Biológicas de tres universidades de Recife (Brasil) para evaluar sus percepciones en relación con el mercado de trabajo, área de actuación y reglamentación de la profesión. Observamos que la gran mayoría desconoce su perfil de actuación, y confunde las competencias de los biólogos con las de otros profesionales. Existe un buen conocimiento sobre el órgano reglamentador, pero la inmensa mayoría desconoce el piso salarial mínimo de la categoría. Preguntados sobre la motivación para la elección del curso, la respuesta mas frequente fue la de desenvolver investigación, y la carrera de investigador fue la principal meta de los estudiantes entrevistados. Se sugiere, por lo tanto, la inserción de temas relacionados a la reglamentación de la profesión del biólogo, con énfasis en la legislación y la ética, en disciplinas específicas o actividades complementares a lo largo del curso, para perfeccionar la formación académica percibida.

Palabras-clave: evaluación, graduado, mercado, actuación, reglamentación, biólogo.

\begin{abstract}
Any evaluation of the quality of higher education demands much more than a test on "technical" knowledge acquired at the university. It is essential for professionals to know exactly where they can work, what their professional legal status is, and what they are entitled or not to do. In this context, we conducted a research with students working towards a Bachelor in Biology degree at three higher education institutions in Recife, in the state of Pernambuco, in order to evaluate their perceptions of the labor market, their possible areas of performance and the regulation of their profession. We noticed that the majority does not know their performance profile, and confuses the biologist's competences with those of other professionals. They have some good knowledge about the institution that regulates the profession, but most students are unaware of the profession's minimum wage. When they were questioned about their reasons for choosing the course, the intention of doing research was the most frequent answer, and the career of researcher is the main target of the interviewees. It is suggested that topics related to the regulation of the biologist's profession, with an emphasis on ethics and legislation, be included either in specific courses or in complementary activities, in order to improve their academic formation.
\end{abstract}

Key words: evaluation, Bachelor, market, performance, regulation, biologist. 


\section{INTRODUÇÃO}

Um dos grandes desafios do ensino superior brasileiro é a sua função estratégica de fornecer subsídios para que a inserção do indivíduo no mercado de trabalho seja imediata, produtiva e comprometida com o bem-estar social. Embora diversos estudos detectem o efeito da formação universitária no aumento da empregabilidade e no salário médio do profissional (Avena, 2004), percebe-se na estrutura curricular da maioria dos cursos uma lacuna na formação do graduando que não recebe orientação voltada à prática e a questões de atuação profissional. Aspectos ligados à ética e à regulamentação profissional tendem a ser largamente ignorados em prol de uma formação cada vez mais técnica, mesmo considerando que para o recém-formado o conhecimento da legislação pertinente à sua profissão é tão importante quanto o conteúdo científico acumulado ao longo do curso.

O Bacharelado em Ciências Biológicas é um exemplo claro de confusão conceitual quanto à área de atuação e empregabilidade, uma vez que a natureza inter e multidisciplinar do biólogo interage e intersecta funções tradicionalmente exercidas por biomédicos, agrônomos, veterinários, geólogos, nutricionistas e médicos, entre outros. A profissão do biólogo foi criada pela Lei n. 6.684, de 3 de setembro de 1979; entretanto, somente em 1983, após sua regulamentação por meio do Decreto n. 88.438/83, ocorreu a criação do Conselho Federal de Biologia. Determinouse, assim, as áreas de atividade e previram-se as possibilidades de sua atuação na elaboração de projetos de pesquisa, orientação e assessoria a empresas, realização de perícias e assinatura de laudos nas diversas áreas do conhecimento biológico (Brasil, 2006).

O biólogo caracteriza-se por ser um profissional atualizado, com formação sólida dos princípios e das teorias da biologia, capaz de atuar, tanto em nível técnico quanto experimental, na elaboração e execução de projetos e com capacidade de relacionar ciência, tecnologia e sociedade, analisando as implicações sociais do conhecimento e de seu uso. Sua formação deve assegurar conhecimentos básicos, entre outros, de Física, Química, Matemática e Ciências Humanas para permitir o entendimento das complexas e multifacetadas interações que envolvem os seres vivos.

Esta profissão tem recebido, nos últimos anos, maior destaque da mídia, como conseqüência do desenvolvimento científico e tecnológico, com ampliação dos seus campos de atuação. Temas recentes, como o extraordinário avanço das aplicações da Genética, a explosão da Biotecnologia como ferramenta para manipulação e produção de organismos e seus derivados, e uma visão mais crítica e quantitativa das 
questões ambientais, onde se revela a fragilidade dos ecossistemas sob ação humana, despertaram e multiplicaram os desafios a serem enfrentados pelo biólogo. Isso resultou em um renovado interesse e uma crescente demanda de vagas nos concursos vestibulares. No entanto,

O trabalho profissional dos biólogos ainda é pouco conhecido e reconhecido pelo grande público, que muitas vezes não está familiarizado com suas múltiplas atribuições prevista na lei. Este é um dos fatores que dificultam a inserção dos biólogos no mercado de trabalho, principalmente em áreas de competência já ocupadas por outros profissionais. Há portanto necessidade de consolidar a imagem profissional junto à sociedade e de preparar os futuros biólogos para os desafios que enfrentarão após a conclusão do curso. (Rosa, 2000, p. 63)

Segundo o MEC/Sesu, o profissional da área de Ciências Biológicas está atualmente sendo formado por mais de 400 cursos de graduação (entre bacharelado e licenciatura), em diversas faculdades e universidades, localizadas em todas as regiões do país (Brasil, 2006). Muitos desses cursos oferecem a formação integrada de Bacharel e Licenciado, embora a tendência seja separar as duas formações em cursos distintos. Uma característica comum à grande parte dos cursos é a existência de uma lacuna na formação do biólogo, em razão da falta de uma disciplina sobre ética, que prepare o futuro biólogo para sua conduta profissional, instruindo-o, ainda, sobre a legislação específica da sua área de conhecimento.

Partindo dessas inquietações, o objetivo desta pesquisa foi contribuir para o debate sobre o compromisso com a formação do profissional, avaliando as percepções e expectativas dos bacharelandos em Ciências Biológicas. Acreditamos que a avaliação da qualidade do curso (e do graduado, por sua vez) exige a inserção de critérios relacionados à formação ético-legal que o graduando recebe em sua instituição. Dessa forma, nossa pesquisa buscou analisar os seguintes aspectos: a motivação da escolha do curso, as perspectivas profissionais, o conhecimento sobre a área de atuação e o conhecimento sobre a regulamentação da profissão do biólogo entre graduandos de Recife.

Deve-se destacar que a pesquisa não teve qualquer intenção de avaliar a qualidade dos cursos pesquisados, nem pretendeu assumir uma postura crítica com relação às estruturas curriculares ou coordenações de cada instituição. Nossa intenção foi traçar um painel mais abrangente sobre a formação recebida pelos biólogos, na cidade do Recife, especialmente em relação a temas pouco explorados, como a legislação aplicada ao biólogo. 


\section{MATERIAL E MÉTODOS}

\section{Instituições de Ensino Pesquisadas}

Esta pesquisa descritiva foi realizada em janeiro e fevereiro de 2005, tendo como instrumento de coleta de dados um questionário aplicado a estudantes de Bacharelado em Ciências Biológicas de Recife. Foram escolhidas três instituições de ensino superior (IES): a Universidade Federal de Pernambuco (UFPE), sob manutenção federal; a Universidade de Pernambuco (UPE), estadual e também gratuita; e a Faculdade Franssinetti do Recife (Fafire), estabelecimento de natureza comunitária, mantido pela ordem religiosa das Dorotéias.

A estrutura curricular dos cursos, em cada uma das instituições, varia grandemente, com ênfase à pesquisa em Biodiversidade e Genética na UFPE, e à Saúde na UPE e na Fafire. Apesar disso, a duração média dos cursos é a mesma nas três IES, ou seja, cerca de quatro anos, e todos os cursos são oferecidos no período diurno. O curso contava, no período da pesquisa, com aproximadamente 360 alunos na UFPE, 240 na UPE e 360 na Fafire. Foram entrevistados 100 estudantes da UFPE $(27,8 \%$ dos alunos regularmente matriculados), 93 da UPE $(38,8 \%)$ e 78 da Fafire $(21,7 \%)$.

\section{Instrumento de coleta de dados}

O questionário abordava quatro eixos temáticos sobre o papel do biólogo: 1) motivações para a escolha da profissão e fontes de informação sobre o curso; 2) perspectivas de trabalho (incluindo destino, dificuldades e expectativas) ao concluir o curso; 3) nível de conhecimento sobre a área de atuação do biólogo; e, por último, 4) grau de informação sobre a regulamentação da profissão. A maioria das questões foi de natureza objetiva, visando a acelerar o preenchimento, havendo, no entanto, ao longo do questionário, espaços disponíveis para comentários adicionais dos respondentes.

O questionário foi distribuído a alunos das três instituições, buscando equalizar e maximizar o número de alunos por período, respeitando-se a proporção entre eles. A elaboração das categorias de nível de conhecimento foi realizada de acordo com as respostas obtidas em testes piloto. Para categorizar algumas respostas, foi utilizado o seguinte critério: nível de conhecimento ou informação ruim ( $<25 \%$ de respostas corretas), regular (de $26 \%$ a $50 \%$ ), bom (de $51 \%$ a $75 \%$ ) e excelente (acima de $75 \%$ das respostas corretas). 
O questionário foi aplicado nas próprias instituições, em geral nas áreas de uso comum, como corredores, bibliotecas, centros de convivência e lanchonetes, nos intervalos de aula, a fim de não tumultuar as atividades didáticas em andamento. A adesão foi voluntária e a resolução durou, em média, de 5 a 10 minutos. Para garantir a fidedignidade das respostas e o respeito ao entrevistado, manteve-se o anonimato dos respondentes ao longo de toda a pesquisa.

\section{RESULTADOS E DISCUSSÃO}

\section{Motivação para escolha e fontes de informação sobre o curso}

Quando indagados sobre suas motivações para a escolha do Bacharelado em Ciências Biológicas, houve um certo equilíbrio nas respostas das três instituições e entre as três respostas mais citadas (Tabela 1), sendo o interesse em realizar descobertas científicas a motivação mais freqüente, seguida do interesse em trabalhar na área ambiental e em Biotecnologia.

Tabela 1 - Perfil geral dos bacharelandos em Ciências Biológicas da UPE, UFPE e Fafire em relação à motivação para escolha do curso, fontes de informação e expectativas profissionais

\begin{tabular}{|c|c|c|}
\hline Tópicos & Respostas mais freqüentes & $\begin{array}{c}\text { Percentual de } \\
\text { respostas (média) } \\
(\mathrm{N}=371)\end{array}$ \\
\hline \multirow{3}{*}{$\begin{array}{l}\text { Motivações para escolha do } \\
\text { curso de Bacharelado em } \\
\text { Biologia }\end{array}$} & $\begin{array}{l}\text { Interesse em realizar pesquisas e fazer } \\
\text { descobertas científicas }\end{array}$ & 22,8 \\
\hline & $\begin{array}{l}\text { Atuar na preservação da natureza/meio } \\
\text { ambiente }\end{array}$ & 21,8 \\
\hline & Trabalhar na área da Biotecnologia & 20,0 \\
\hline \multirow{3}{*}{$\begin{array}{l}\text { Fontes de informação sobre } \\
\text { a profissão de Biólogo }\end{array}$} & Universidade/Faculdade & 37,2 \\
\hline & Internet & 20,2 \\
\hline & Revistas/Livros & 15,5 \\
\hline \multirow{3}{*}{$\begin{array}{l}\text { Destino pretendido após a } \\
\text { conclusão do curso }\end{array}$} & Pós-graduação & 36,0 \\
\hline & Órgãos de pesquisa (Ex.: Fiocruz, Embrapa) & 30,0 \\
\hline & Órgãos públicos (Ex.: Ibama, Secretaria de Saúde) & 19,5 \\
\hline \multirow{3}{*}{$\begin{array}{l}\text { Expectativa de conseguir } \\
\text { emprego na área }\end{array}$} & Não tenho certeza & 47,3 \\
\hline & Sim, de 6 meses a 1 ano & 31,1 \\
\hline & Com certeza, em até 6 meses & 15,9 \\
\hline \multirow{3}{*}{$\begin{array}{l}\text { Maiores dificuldades na } \\
\text { profissão de biólogo }\end{array}$} & Desvalorização da categoria & 26,7 \\
\hline & Desemprego & 23,6 \\
\hline & Baixa remuneração & 17,2 \\
\hline
\end{tabular}


Durante as entrevistas, muitos bacharelandos afirmaram que escolheram Biologia como "segunda opção", por não terem sido aprovados em outros cursos tradicionalmente considerados de maior prestígio (ex. Medicina), mas acabaram se encantando com o curso e valorizando-o à medida que cumpriam as disciplinas Em pesquisa conduzida entre licenciandos em Ciências Biológicas na UFPE, Vasconcelos (2000) detectou fenômeno semelhante: $81,0 \%$ dos alunos haviam prestado vestibular para outros cursos na área de Saúde, como Medicina (42,0\%) e Odontologia $(15,0 \%)$.

Os alunos entrevistados apontam a instituição de ensino como principal fonte de informação sobre a profissão de biólogo, sua área de atuação e mercado de trabalho, embora tenham afirmado ter entrado na IES ainda incertos sobre o perfil do curso. É comum haver, no primeiro semestre, nas três IES, palestras sobre o curso e a profissão, com a presença freqüente de representantes de entidades profissionais. Isso favorece uma compreensão mais realista sobre a área de atuação, embora ao longo do curso tais iniciativas nem sempre sejam mantidas.

\section{Perspectivas profissionais}

Embora a profissão do biólogo tenha recebido nos últimos anos maior destaque da mídia em razão do desenvolvimento científico e tecnológico, com ampliação dos campos de atuação, 47,3\% dos graduandos não têm certeza quanto ao imediato ingresso no mercado de trabalho. Talvez, reconhecendo a qualidade da IES à qual está vinculado, quase um terço deles afirma ter certeza de conseguir emprego em sua área no máximo um ano após a conclusão de curso (Tabela 1). Vasconcelos (2000) registrou um otimismo ainda maior entre licenciandos em Ciências Biológicas da UFPE: 98,0\% dos alunos acreditavam que iriam conseguir emprego em sua área de atuação ao terminar o curso. O nível de empregabilidade de licenciandos é, na verdade, bastante superior ao dos bacharelandos, pois envolve todas as atividades deste último e ainda o ensino básico. A absorção dos licenciandos é tamanha que mesmo durante a graduação os alunos já conseguem emprego como professores ou estagiários em escolas. Na UFPE, mais de um terço dos licenciandos em Biologia já trabalha em ensino (Vasconcelos, 2000). Na UFPE, um dos questionamentos mais comuns entre bacharelandos em Ciências Biológicas é justamente o fato de sua carga horária ser praticamente a mesma da Licenciatura e sua atuação ser mais limitada, ressaltando a necessidade de esclarecimentos mais precisos. 
Como linha de trabalho e destino pretendido após a graduação, houve clara predominância de atividades de pesquisa pelos estudantes dos três cursos. A grande maioria (quase dois terços) pretende seguir carreira de pesquisador; para isso, $36,0 \%$ dos entrevistados pretendem realizar pósgraduação imediatamente após o término do curso. O emprego mais citado pelos entrevistados foi o de professor universitário. Também, para boa parte dos licenciandos, ser professor universitário configura-se como o ponto máximo da carreira. Vasconcelos (2000) observou que 100\% dos licenciandos em Biologia entrevistados pretendiam realizar Mestrado e Doutorado, pois têm interesse em ser docentes universitários. Talvez como reflexo do desconhecimento de outras áreas de atuação, mais "aplicadas", menos de um quinto dos bacharelandos entrevistados afirmou pretender trabalhar em consultorias e outras ocupações "não-acadêmicas". Isso reflete um desconhecimento do potencial de absorção de biólogos em indústrias, empresas, organizações não-governamentais e até no setor de serviços, como turismo ecológico.

Entre as maiores dificuldades citadas pelos estudantes está a desvalorização da categoria $(26,7 \%)$, seguida de perto pela questão do desemprego (Tabela 1). Naturalmente, o desemprego atinge uma significativa parcela da população brasileira, independentemente do curso. Entretanto, segundo Gomes (1988), biólogos nem sempre conseguem uma condição profissional satisfatória. Isso reflete a disparidade com outros cursos, como Medicina e Odontologia, em que quase a totalidade consegue uma ocupação condizente à sua formação. Evidencia-se, assim, que os egressos de cursos com absorção mais imediata ou de melhor "imagem" de mercado têm êxito profissional mais rápido e consistente.

Quanto ao nível de conhecimento dos estudantes de Biologia sobre sua área de atuação, pode-se dizer que ao final do curso os graduandos não conseguem distinguir sua real identidade profissional, pela falta de clareza das habilidades e competências obtidas e a pequena diferenciação da demanda de cada profissão no mercado de trabalho. De acordo com Gondim (2002), o estudante acredita que o mercado confunde os papéis profissionais por desconhecer suas especificidades, como as atividades exercidas por biólogos bacharéis e licenciados, agrônomos, biomédicos e outros. Por outro lado, ao ser perguntado sobre o seu papel profissional, o próprio bacharelando tem dificuldade em explicitá-lo claramente.

Isso pode ser observado na Tabela 2, onde as médias dos menores índices de acertos nas três instituições foram: atuar como promotor em processos ou questões ambientais $(10,4 \%)$, supervisionar a produção agrícola $(16,7 \%)$, receitar fertilizantes, inseticidas e outros insumos agrícolas $(30,6 \%)$ e ministrar aulas no ensino médio $(40,8 \%)$. Em contrapartida, as 
áreas de domínio técnico definido demarcam mais precisamente suas atuações e não colocam em dúvida a diferença entre um biólogo bacharel e um médico veterinário, por exemplo. Segundo Gílio (2000), isso traz à tona uma importante questão: por um lado, a crescente demanda de um perfil multiprofissional e, por outro, o aumento da fragilização dos limites profissionais de algumas áreas de atuação.

Tabela 2 - Nível de conhecimento (em \% de acertos) de bacharelandos em Ciências Biológicas sobre sua área de atuação, de acordo com a IES. Os exemplos de atuações tinham três opções de resposta: $A=$ "Somente por bacharéis em Ciências Biológicas"; $B$ = "Permitido, porém não exclusivo a bacharéis em Ciências Biológicas"; $C=$ "Não permitido a bacharéis em Ciências Biológicas". Como parte da avaliação, foram apresentadas apenas opções de atuação com respostas corretas nos itens " $\mathrm{B}$ " $\mathrm{e}$ " $\mathrm{C}$ "

\begin{tabular}{|c|c|c|c|c|}
\hline \multirow{2}{*}{$\begin{array}{l}\text { Resposta } \\
\text { Correta }\end{array}$} & \multirow{2}{*}{ Atuação profissional } & \multicolumn{3}{|c|}{$\begin{array}{l}\text { Instituição/ } \\
\text { \% de acertos }\end{array}$} \\
\hline & & $\begin{array}{c}\text { UFPE } \\
(\mathrm{N}=100)\end{array}$ & $\begin{array}{c}\text { UPE } \\
(\mathrm{N}=93)\end{array}$ & $\begin{array}{l}\text { Fafire } \\
(\mathrm{N}=78)\end{array}$ \\
\hline \multirow{7}{*}{$\begin{array}{l}\text { Permitido, } \\
\text { porém não } \\
\text { exclusivo a } \\
\text { Bacharéis } \\
\text { em Ciências } \\
\text { Biológicas }\end{array}$} & Ministrar aula no ensino superior & 64,6 & 50,5 & 53,8 \\
\hline & Realizar análises clínicas & 54,5 & 64,5 & 48,7 \\
\hline & Diagnosticar perícias criminais & 64,6 & 55,9 & 37,2 \\
\hline & $\begin{array}{l}\text { Responsabilizar-se ou criar/cultivar } \\
\text { animais e plantas para comercialização }\end{array}$ & 59,6 & 53,8 & 50,0 \\
\hline & Elaborar relatórios de impacto ambiental & 57,6 & 49,2 & 53,8 \\
\hline & Inspecionar a qualidade de alimentos & 66,7 & 73,1 & 43,6 \\
\hline & Elaborar projetos de paisagismo & 57,6 & 60,2 & 37,2 \\
\hline \multirow{7}{*}{$\begin{array}{l}\text { Não } \\
\text { permitido a } \\
\text { Bacharéis } \\
\text { em Ciências } \\
\text { Biológicas }\end{array}$} & Ministrar aula no ensino médio & 33,3 & 43,0 & 46,2 \\
\hline & $\begin{array}{l}\text { Atuar como promotor em processos ou } \\
\text { questões ambientais }\end{array}$ & 15,2 & 10,8 & 5,1 \\
\hline & Diagnosticar causa de morte em hospitais & 51,5 & 45,2 & 33,3 \\
\hline & Supervisionar produção agrícola & 18,2 & 14,0 & 18,0 \\
\hline & Projetar instalações para biotérios & 57,6 & 43,0 & 39,5 \\
\hline & Receitar medicamentos veterinários & 74,8 & 72,0 & 53,8 \\
\hline & $\begin{array}{l}\text { Receitar fertilizantes, inseticidas e outros } \\
\text { insumos agrícolas }\end{array}$ & 37,4 & 31,1 & 23,4 \\
\hline
\end{tabular}

Na Tabela 3 observamos o nível de conhecimento dos estudantes de Biologia das três IES a respeito da regulamentação da profissão do biólogo. Em relação ao conhecimento do piso salarial mínimo, nenhuma das IES 
obteve resultado satisfatório: enquadraram-se na categoria "ruim" a UFPE (13,3\% de respostas corretas), a UPE ( $8 \%$ ) e a Fafire (3,8\%).

Já em relação ao conhecimento sobre o órgão regulamentador, notouse que os estudantes da UPE obtiveram, em média, o melhor resultado $(67,8 \%)$, estando, assim, na categoria de nível "bom", seguida pela Fafire, com média de 52,4\%. Também não foi encontrada associação entre o nível de conhecimento da regulamentação da profissão e o ano letivo (Tabela 3). Não se pode, entretanto, assumir que o Bacharelado em Ciências Biológicas está muito mais deficiente que outros cursos. Em pesquisa conduzida com farmacêuticos de Ribeirão Preto, Silva e Vieira (2004) observaram que a maioria dos profissionais demonstrava desconhecimento de sua área de atuação, bem como de aspectos legais relacionados à regulamentação do farmacêutico.

Tabela 3 - Nível de conhecimento dos estudantes de Biologia sobre aspectos da regulamentação da profissão do biólogo, de acordo com a IES e ano letivo no curso

\begin{tabular}{cccccc}
\hline IES & $\begin{array}{c}\text { Ano } \\
\text { letivo }\end{array}$ & $\begin{array}{c}\text { Conhece o órgão } \\
\text { regulamentador? }\end{array}$ & Avaliação & $\begin{array}{c}\text { Conhece o piso } \\
\text { salarial mínimo? }\end{array}$ & Avaliação \\
\hline \multirow{2}{*}{ UFPE } & $1^{\circ}$ & $60,8 \%$ & Bom & $17,4 \%$ & Ruim \\
$(\mathrm{N}=100)$ & $2^{\circ}$ & $68,2 \%$ & Bom & $9,1 \%$ & Ruim \\
& $3^{\circ}$ & $37,9 \%$ & Regular & $17,2 \%$ & Ruim \\
& $4^{\circ}$ & $33,3 \%$ & Regular & $9,5 \%$ & Ruim \\
\hline \multirow{3}{*}{ UPE } & $1^{\circ}$ & $25,0 \%$ & Ruim & $4,2 \%$ & Ruim \\
$(\mathrm{N}=93)$ & $2^{\circ}$ & $88,2 \%$ & Ótimo & $2,9 \%$ & Ruim \\
& $3^{\circ}$ & $83,3 \%$ & Ótimo & $12,5 \%$ & Ruim \\
& $4^{\circ}$ & $75,0 \%$ & Bom & $12,5 \%$ & Ruim \\
\hline \multirow{3}{*}{ Fafire } & $1^{\circ}$ & $45,4 \%$ & Regular & $6,1 \%$ & Ruim \\
$(\mathrm{N}=78)$ & $2^{\circ}$ & $17,6 \%$ & Ruim & $3,0 \%$ & Ruim \\
& $4^{\circ}$ & $66,6 \%$ & Bom & $6,1 \%$ & Ruim \\
& & $80,0 \%$ & Ótimo & $0 \%$ & Ruim \\
\hline
\end{tabular}

\section{Como formar biólogos conscientes de sua atuação profissional?}

Uma das soluções para minimizar a desinformação sobre a legislação e a atuação da profissão do biólogo é a inclusão de uma disciplina que 
prepare o futuro biólogo para a sua conduta profissional, instruindo-o principalmente sobre a legislação específica da sua área de conhecimento. Como exemplo, temos a Universidade Federal de Santa Catarina (UFSC) que, em 1993, inseriu na graduação em Ciências Biológicas a disciplina de "Ética e Legislação Profissional". Esta contempla a análise de legislação e normas que regulamentam a orientação e atividade profissional, a discussão sobre formas de inserção do biólogo na sociedade e o debate sobre a participação do biólogo nos órgãos profissionais da categoria, incluindo Código de Ética e Direito (Rosa, 2000).

Formação complementar, extracurricular, é tradicionalmente oferecida na forma de eventos, como semanas pedagógicas, ciclos de palestras, ações extensionistas, encontros de estudantes e profissionais de Biologia, entre outros. Embora não supram a carência existente no curso formal, certamente minimizam o desconhecimento sobre tais temas. Nas IES pesquisadas, os estudantes novatos participam de palestras com representantes do Conselho Regional de Biologia da 5a Região, que inclui os Estados do Nordeste. Os profissionais do CRBio-5 estão sempre disponíveis para participar de eventos informativos, disponibilizando também material e informações por telefone, correio eletrônico e na home page.

Talvez a inserção de uma disciplina específica pudesse preencher esta lacuna, embora se reconheça a saturação da estrutura curricular dos cursos em questão. Em uma situação ideal (porém pouco prática), seria mais produtivo expor o aluno ao seu campo de atuação ao longo de todo o curso, nas próprias disciplinas, em estágios, orientações dos supervisores e outras oportunidades. Uma ferramenta vital neste processo, menos explorada em instituições particulares e comunitárias, compreende a extensão. Quando o aluno se envolve desde cedo em atividades práticas, de resolução de problemas, envolvendo a comunidade externa, certamente criará oportunidades de conhecer melhor sua "real" atuação, além da acadêmica. Um benefício imediato dessas práticas combinadas (disciplinas, eventos, extensão, palestras) seria a redução da evasão, hoje um problema crônico em inúmeros cursos. Ao saber logo no início qual a função de um biólogo profissional, o aluno irá se identificar mais rapidamente e, conseqüentemente, investir no curso, ou, caso contrário, optar por outra área do conhecimento. Naturalmente, o desejável é que os estudantes ingressem na IES plenamente informados do que os espera, e, nesse aspecto, os órgãos de representação, as coordenações de curso e os diretórios/centros acadêmicos devem cumprir o papel de instruir sobre a responsabilidade e a área de atuação do biólogo.

Nas IES pesquisadas existem iniciativas desta natureza. Na UFPE, por exemplo, há a Semana de Ciências Exatas e da Natureza em que 
concluintes do ensino médio da rede pública são convidados a visitar as dependências da universidade onde, em stands organizados pelos próprios graduandos, aprendem sobre os cursos oferecidos nas áreas de Física, Química, Biologia e Matemática. O evento é gratuito e conta com a participação de milhares de alunos em exposições interativas, palestras e mini-cursos.

\section{CONSIDERAÇÕES FINAIS}

A universidade de hoje baseia-se em um modelo - ensino, pesquisa e extensão - que pressupõe uma estrutura complexa, com suas faculdades, institutos, departamentos, além de múltiplos órgãos necessários ao cumprimento de sua missão e ao atendimento de suas especificidades; desse modo, a avaliação é algo que se impõe para fins de planejamento e ação (Vianna, 2004). O cumprimento desta função exige um monitoramento constante da "qualidade do produto" gerado, para evitar "desperdícios" de tempo e recursos. A avaliação vai permitir que a universidade identifique suas necessidades, que são múltiplas e variadas.

A avaliação dos cursos superiores necessita incluir, de alguma forma, a preparação recebida pelo graduando para o exercício de sua profissão. Isso vai além da competência "técnica", o acúmulo de informações e conhecimentos necessários para o entendimento dos fenômenos biológicos. Exige que o saber utilize esses conhecimentos de forma sistematizada, assimilável e utilizável pela sociedade. Um profissional - seja qual for sua área de atuação - que desconhece os parâmetros básicos da sua área de atuação certamente estará em desvantagem em sua inclusão no mercado.

Como ressaltado no início, esta pesquisa não tem qualquer interesse em apontar as falhas na formação do profissional. Acreditamos que uma (auto) avaliação de nosso papel como formadores requer um diagnóstico mais preciso da questão. Conforme ressalta Vianna (2004), a universidade com seus cursos, programas, currículos e disciplinas precisa criar condições para funcionar satisfatoriamente, pois, para a realização dos seus objetivos básicos, necessita de uma estrutura curricular e de um ambiente profissionalizante que constantemente se renove e atualize os seus conhecimentos. 


\section{REFERÊNCIAS BIBLIOGRÁFICAS}

AVENA, C. P. Demanda por ensino superior: o caso da Universidade Federal da Bahia. Estudos em Avaliação Educacional, n. 29, p. 111-135, jan./jun. 2004.

BRASIL. Ministério da Educação e do Desporto. Secretaria de Educação Superior. Padrões de Qualidade. Padrões do Curso de Ciências Biológicas. Disponível em: http://portal.mec.gov.br/sesu/arquivos/pdf/padbiol.pdf Acesso em: 6 fev. 2006.

GÍLIO, I. Trabalho e educação: formação profissional e mercado de trabalho. São Paulo: Nobel, 2000, 110p.

GOMES, C. A. Curso superior e mobilidade social: vale a pena? Educação Brasileira, Brasília, DF, v.10, n.20, p.63-76, 1988.

GONDIM, S. M. G. Perfil profissional e mercado de trabalho: relação com formação acadêmica pela perspectiva de estudantes universitários. Estudo de Psicologia, v. 7, n. 2, p. 299-309, jul./dez. 2002.

ROSA, V. L. Promovendo a profissionalização do biólogo: inserção da disciplina "Ética e Legislação Profissional" no curso de Ciências Biológicas da UFSC. In: ENCONTRO PERSPECTIVAS DO ENSINO DE BIOLOGIA, 7. Anais do... São Paulo, 2000, p. 62-64.

SILVA, L. R.; VIEIRA, E. M. Conhecimento dos farmacêuticos sobre legislação sanitária e regulamentação da profissão. Revista de Saúde Pública, v. 3, n. 38, p. 429-437, 2004.

VASCONCELOS, S. D. Re-estruturação do curso de Licenciatura em Ciências Biológicas da UFPE. In: ENCONTRO PERSPECTIVAS DO ENSINO DE BIOLOGIA, 7. Anais do... São Paulo, 2000, p. 378-384.

VIANNA, H. M. Avaliação de cursos pelos alunos: considerações. Estudos em Avaliação Educacional, n. 29, p. 137-148, jan./jun. 2004.

Recebido em: março 2006

Aprovado para publicação em: julho 2006 
